\title{
The exchange across the tropical tropopause in overshooting convective cores
}

\author{
T. N. Rao, B. Radhakrishna, T. Mohan Satyanarayana, and S. Satheesh Kumar \\ National Atmospheric Research Laboratory, Gadanki - 517 112, India
}

Received: 10 September 2009 - Revised: 15 December 2009 - Accepted: 2 January 2010 - Published: 18 January 2010

\begin{abstract}
Coordinated measurements of Indian MST radar and radiosonde during the passage of overshooting convective cores in SAFAR pilot campaign (May-November 2008) are utilized to quantify the mass flux across the tropopause and strength of the turbulence in up- and down-draft cores. The distribution of retrieved mass flux is found to be wide, ranging from -0.6 (downward flux) to $0.8 \mathrm{~kg} \mathrm{~m}^{-2} \mathrm{~s}^{-1}$ (upward flux). The net mass flux, is, however, from the troposphere to stratosphere, in spite of the existence of significant amount of downward flux. For the first time, the turbulence strength in the vicinity of the tropopause in convective cores is quantified. Large spectral widths with magnitudes $>4 \mathrm{~m} \mathrm{~s}^{-1}$ are observed during convection. However, such large spectral widths are rare and are observed only for $1.6 \%$ of total observations. The average spectral width (and also the variation or standard deviation) in draft cores is found to be $\sim 4.5$ times larger than that in fair-weather. The turbulence strength in updraft cores is much higher than that of in downdraft cores. The mean (median) spectral width in updraft cores is larger by $\sim 0.8 \mathrm{~m} \mathrm{~s}^{-1}$ (a factor of $\sim 2$ ) than that of in downdraft cores. The turbulence strength does not show any systematic variation with the intensity of convection in both up- and down-draft cores. The distributions and mean values of mass flux and turbulence strength obtained in the present study will be useful to quantify the STE due to direct intrusion of mass by overshooting convection and the exchange of constituents (in particular water vapor) due to turbulence in a better way.
\end{abstract}

Keywords. Meteorology and atmospheric dynamics (Convective processes; Middle atmosphere dynamics; Turbulence)

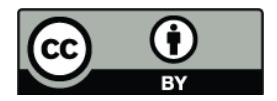

Correspondence to: T. N. Rao (tnrao@narl.gov.in)

\section{Introduction}

There is a renewed interest on the exchange between the troposphere and stratosphere (STE) in recent years because of the intriguing processes occurring in this region, such as ozone depletion in extratropics, dehydration of air in tropics, etc. On a climatological scale, the mean transport is from the troposphere to stratosphere in tropics and from stratosphere to troposphere in extratropics, primarily controlled by the diabatic stratospheric circulation (Holton et al., 1995). Earlier studies used a variety of methods to quantify the mass flux across the tropopause and found that the flux due to diabatic circulation is from the troposphere to stratosphere in tropics (Rosenlof, 1995; Sherwood, 2000). These studies have shown that tropical diabatic mean lift and mass fluxes are about half as strong in northern summer as in northern winter. Nevertheless, small-scale processes occurring near the tropopause also play a crucial role in the transportation of constituents and the exchange between these two important layers. However, quantification of exchange by these processes is difficult, because of their variability in space, time and the magnitude. In tropics, these processes include deep penetrative convection (Jain et al., 2001; Kumar, 2006) and enhanced turbulence mixing induced by wave breaking ( $\mathrm{Fu}-$ jiwara et al., 2003) and shear instabilities.

The overshooting convection can influence the STE processes in several ways; transportation of mass and constituents from the troposphere to stratosphere and also from the stratosphere to troposphere, through enhanced turbulent mixing, and gravity wave generation and/or filtering. Most importantly, penetrative convection can hydrate/dehydrate the air entering into the stratosphere and this issue will be discussed in detail later. Several modeling and experimental studies dealt with the characteristics of gravity waves generated by convection (CGW) and their transport of energy and momentum across the tropopause (Alexander et al., 1995; Dhaka et al., 2002; Kishore, 2006). Other studies focused on

Published by Copernicus Publications on behalf of the European Geosciences Union. 
Table 1. Important specifications and parameters of IMSTR used in the present study.

\begin{tabular}{ll}
\hline Parameter & MST radar \\
\hline Frequency & $53 \mathrm{MHz}$ \\
Peak Power & $2.5 \mathrm{MW}$ \\
Beam width & $3^{\circ}$ \\
Inter pulse period & $250 \mu \mathrm{s}$ \\
Pulse width & $2 \mu \mathrm{s}$ \\
No. Coherent integrations & 128 \\
No. Incoherent integrations & 1 \\
No. FFT points & 512 \\
No. of beams & $4\left(Z_{x}, \mathrm{E} 10, Z_{x}\right.$, and S10) \\
Range resolution & $300 \mathrm{~m}$ \\
\hline
\end{tabular}

the estimation of mass flux across the tropopause in convective cores. These estimates depend heavily on model-derived vertical wind fields, which are generally weak, compared to the observed vertical wind (Rajeevan et al., 2010). There were some flux estimates based on measured vertical winds in convection with air-craft and radars (VHF and Doppler weather radars), but the measurements are limited either to cruising altitudes or to lower/middle troposphere (Lemone and Zipser, 1980; Lucas et al., 1994; May and Rajopadhyaya, 1999; Cifelli et al., 2002, and references therein). Only a few observational studies were available in the literature focusing on mass flux estimations across the tropical tropopause by penetrative convection (Jain et al., 2001; Kumar, 2006). Nevertheless, these studies are based on a few case studies and also used modeled density profiles for estimating the mass flux. One of the objectives of this article (and also SAFAR (Study of Atmospheric Forcing And Responses) program) is to quantify the mass exchange between the troposphere and stratosphere from an ensemble of convection events and concurrent radiosoundings.

In recent years, the role of convection in dehydrating the air entering into the stratosphere is highly debated. It is generally agreed that the tropopause altitude (temperature) is high (cold) in convectively active regions (Gettleman et al., 2002). According to the convective dehydration hypothesis, the air entering into the stratosphere through overshooting convective turrets will be exposed to these extremely cold temperatures resulting into the formation of ice, which will sediment out leaving dry air behind in the stratosphere (Danielsen, 1993; Sherwood and Dessler, 2001). In contrast, a few studies have shown that the convection hydrates the stratosphere (Corti et al., 2008). Evaporation of condensates and turbulent mixing moistens the upper troposphere and lower stratospheric (UTLS) region. Whether or not the convection hydrates or dehydrates the stratosphere, there is a general consensus that turbulent mixing in the vicinity of the tropopause is one of the primary mechanisms for transferring constituents/watervapor irreversibly. Unfortunately, direct measurements of turbulence in convective cores near the tropical tropopause are scarce. Although the turbulence quantification has been made at various geographical locations in fair weather conditions throughout the troposphere with wind profiling radars (Hocking, 1985; Fukao et al., 1994; Nastrom and Eaton, 1997, 2005; Rao et al., 2001; Fujiwara et al., 2003; Wilson, 2004; Alexander and Tsuda, 2007), the same is not true in convection. Therefore, the second objective of this article is to quantify the turbulence during convection in the UTLS region. Further, some of the intriguing issues are addressed in this article. How intense is convective turbulence in comparison with fair-weather turbulence? Is turbulence strength is same in both up- and downdraft cores? Is magnitude of turbulence depends on convection intensity, gauged by the magnitude of up- and downdrafts?

The data (Indian mesosphere-stratosphere-troposphere (MST) radar - IMSTR and radiosonde) utilized for the present study are described in Sect. 2. The methodology to identify up- and down-draft cores is also briefed in this section. A few case studies, where deep convective cores reached/penetrated the tropopause are described in Sect. 3. It also contains discussion on mass flux and turbulence strength in up- and down-draft cores. Section 4 summarizes all results and discusses future perspectives of SAFAR campaign.

\section{Data and methodology}

The vertical air velocity $(w)$ and spectral width $(\sigma)$ measurements made by the IMSTR during the passage of convection are primarily used in the present study. Complete details of IMSTR can be found in Rao et al. (1995) and the analysis during convection is elaborated in Rao et al. (1999). Important specifications of the radar and parameters used for the present study are shown in Table 1. Every alternate beam is pointed vertically generating vertical air motion profile for every $44 \mathrm{~s}(16 \mathrm{~s}$ for beam probing and $6 \mathrm{~s}$ for data transfer for each beam) with $300 \mathrm{~m}$ height resolution. The beam width of IMSTR is $3^{\circ}$, corresponding to a horizontal width of $800-1000 \mathrm{~m}$ in the tropopause region $(16-20 \mathrm{~km})$. The radar derived $w$ is an average velocity of all scatterer's within the radar resolution volume. The IMSTR measurements are augmented by high-resolution (1-min) surface rainfall rate $(R)$ data obtained by optical rain gauge (ORG-815) and temperature and density $(\rho)$ profiles retrieved from concurrent radiosonde (Meisei-RS01GH) measurements. Note that the IMSTR measures $w$ over the radar location, while radiosonde drifts with background wind. Therefore, $\rho$ derived from radiosonde can be slightly different from that over the radar site (or in cores). For mass flux estimation, the present study assumes the covariance between the density and vertical wind (if any) is negligible.

The IMSTR was kept in alert mode during the SAFAR pilot campaign period (May-November 2008). The radar was 
(a) 21 May 2008

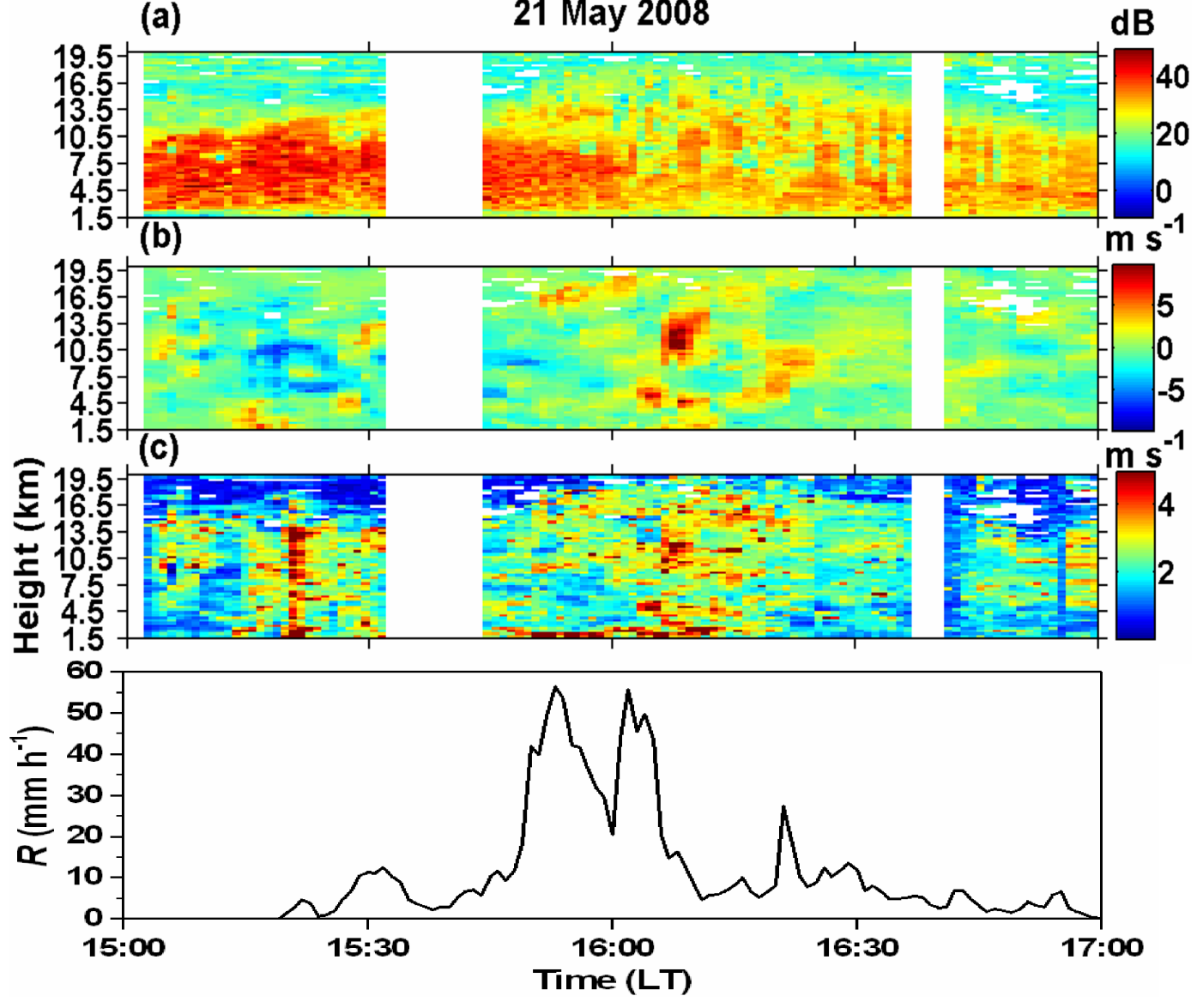

Fig. 1. Time-height contours of (a) range corrected SNR, (b) the vertical air velocity and (c) spectral width observed with the IMSTR on 21 May 2008. The data gaps are shown as white patches. The bottom panel shows temporal variation of surface rainfall derived from ORG.

Table 2. The timings (start and end time) of overshooting in each convection event. The accumulated rainfall during the total event (not only during overshooting period) is also included in the table.

\begin{tabular}{lccc}
\hline \multirow{2}{*}{ Date } & \multicolumn{2}{c}{ Overshooting (LT) } & Accumulated \\
& Start time & End time & rain (mm) \\
\hline 21 May 2008 & $15: 50$ & $16: 15$ & 22.0 \\
7 June 2008 & $21: 35$ & $21: 50$ & 18.4 \\
24 July 2008 & $22: 50$ & $23: 00$ & 17.9 \\
27 July 2008 & $16: 05$ & $16: 20$ & 17.9 \\
24 September 2008 & $14: 30$ & $15: 00$ & 3.5 \\
& $19: 15$ & $2: 240$ & 45.0 \\
\hline
\end{tabular}

operated continuously for more than $6 \mathrm{~h}$ in each event. A total of 16 convection events (10 deep and 6 shallow) were observed during the campaign period, varying in duration from 30 to $220 \mathrm{~min}$. Out of 16 , the convection reached/penetrated the tropopause $(16 \mathrm{~km})$ in 5 cases (see Table 2 for the time and duration of overshooting). Table 2 also contains the accumulated rainfall (in $\mathrm{mm}$ ) during the passage of convection.
The draft core is defined as the region in the time-height intensity map of $w$ in which the absolute value of $w$ is greater than $1 \mathrm{~m} \mathrm{~s}^{-1}$ (Uma and Rao, 2009). To avoid small patches of stronger $w$ to be called as cores, few more constraints are imposed on the definition of core. The core should be persistent for at least $10 \mathrm{~min}$ (in time) and $500 \mathrm{~m}$ (in height). Both upand down-draft cores are identified using the above procedure. The sensitivity of the velocity threshold on core statistics (composite $w$, core overpass duration and core top altitude) is examined by altering the threshold from 1 to 1.5 and to $2 \mathrm{~m} \mathrm{~s}^{-1}$. The above core statistics are not changed much for different thresholds, nevertheless, the number of data points reduced considerably when a $2 \mathrm{~m} \mathrm{~s}^{-1}$ velocity threshold is employed (Uma and Rao, 2009). Since the present study deals with STE, deep convective cores with at least a part of the draft core above $16 \mathrm{~km}$ are only considered here. 


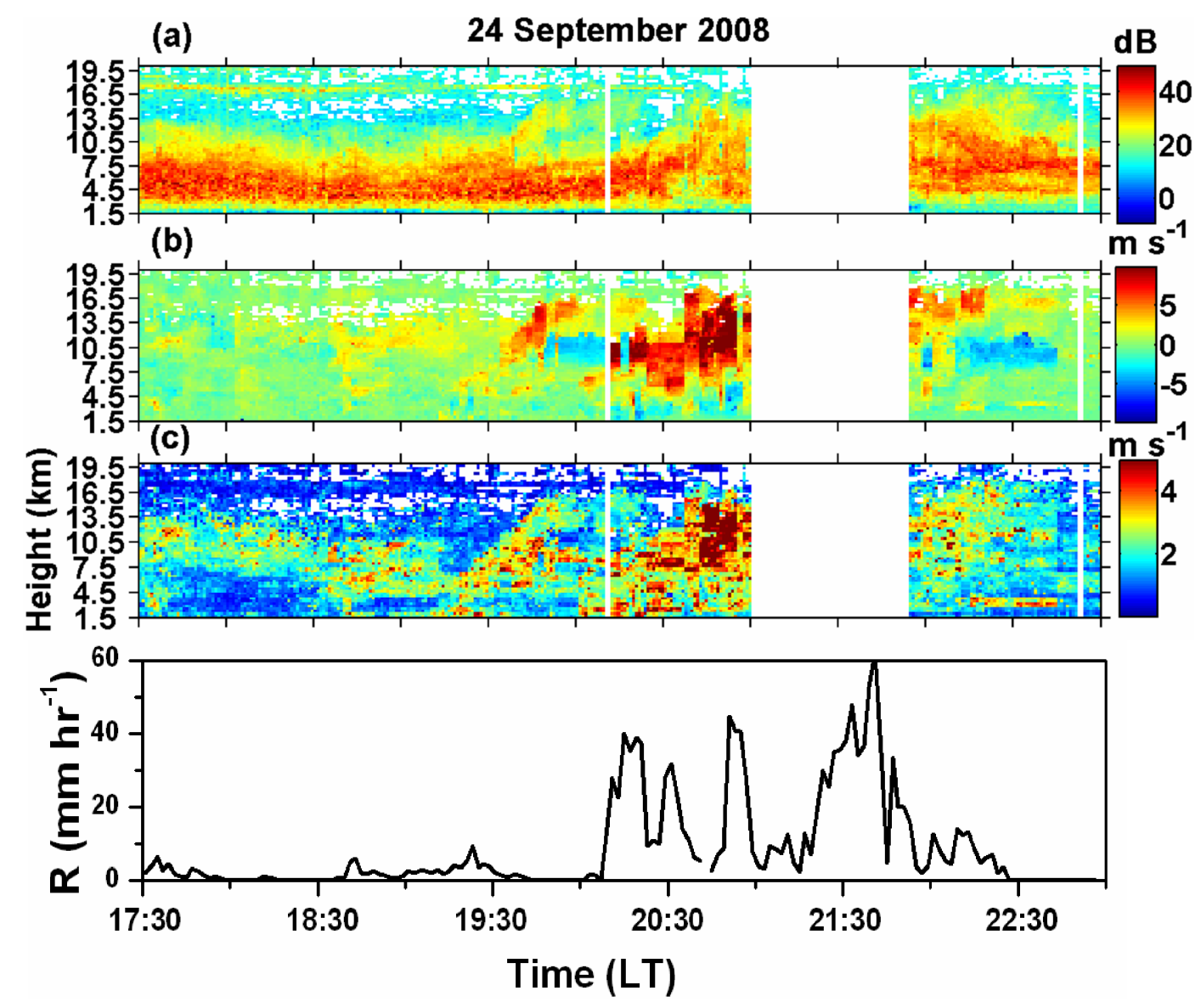

Fig. 2. Same as Fig. 1, but for 24 September 2008.

\section{Results and discussion}

\subsection{Case studies}

Two deep convection events (21 May 2008 and 24 September 2008), during which the convection penetrated the tropopause, are discussed in detail here. The time-height maps of range corrected signal-to-noise ratio (SNR), $w$ and $\sigma$ during the passage of draft cores on 21 May 2008 and 24 September 2008 are shown in Figs. 1 and 2, respectively. The data gaps (2 on 21 May and 1 on 24 September 2008) are due to power failures. On 21 May 2008, convective drafts (both up and down) are seen as patches throughout the observational period. Nevertheless, two cores are clearly apparent from the figure: a weak down-draft core mostly in the middle troposphere (15:15 to $15: 45 \mathrm{LT})$, but extended to the tropopause region for some duration and an intense updraft core (15:50-16:15 LT) throughout the depth of the troposphere. The updrafts during the above period are extended up to the altitude of $\sim 19 \mathrm{~km}$. The intensity of the updraft core is high in the middle troposphere with magnitudes as large as $12 \mathrm{~m} \mathrm{~s}^{-1}$, nevertheless reduced to $1-5 \mathrm{~m} \mathrm{~s}^{-1}$ in the vicinity of the tropopause. Intense surface rainfall with a maximum
$R$ of $\sim 55 \mathrm{~mm} \mathrm{~h}^{-1}$ during 15:50-16:15 LT also corroborates the passage of the convective system. The strength of the turbulence (in terms of spectral width) is also high in both up- and down-draft cores with $\sigma$ values as large as $4 \mathrm{~m} \mathrm{~s}^{-1}$. The variation of surface meteorological parameters and the evolution of this event are discussed in detail in a companion paper (Rajeevan et al., 2010).

The updraft cores on 24 September 2008 show inclined structures with large vertical extension. Two of three cores observed during 18:30-22:30 LT reached the tropopause region. The intensity of the core observed during 20:0021:00 LT is relatively high with $w$ values exceeding $10 \mathrm{~m} \mathrm{~s}^{-1}$ for long period $(\sim 30 \mathrm{~min})$. Large $w$ values are observed in the middle and upper troposphere. In addition to updraft cores, relatively weak downdraft cores (during 19:4020:10 LT and 22:00-22:40 LT) are also present in the middle troposphere. These cores are limited in vertical extension and small in magnitude in comparison with updraft cores. Severe turbulence is observed in updraft cores with $\sigma$ values exceeding $4 \mathrm{~m} \mathrm{~s}^{-1}$. Intense rainfall $\left(R>40 \mathrm{~mm} \mathrm{~h}^{-1}\right.$ for considerable period) is observed during the passage of third core with a rainfall accumulation of $41 \mathrm{~mm}$ in just $21 / 2 \mathrm{~h}$. 


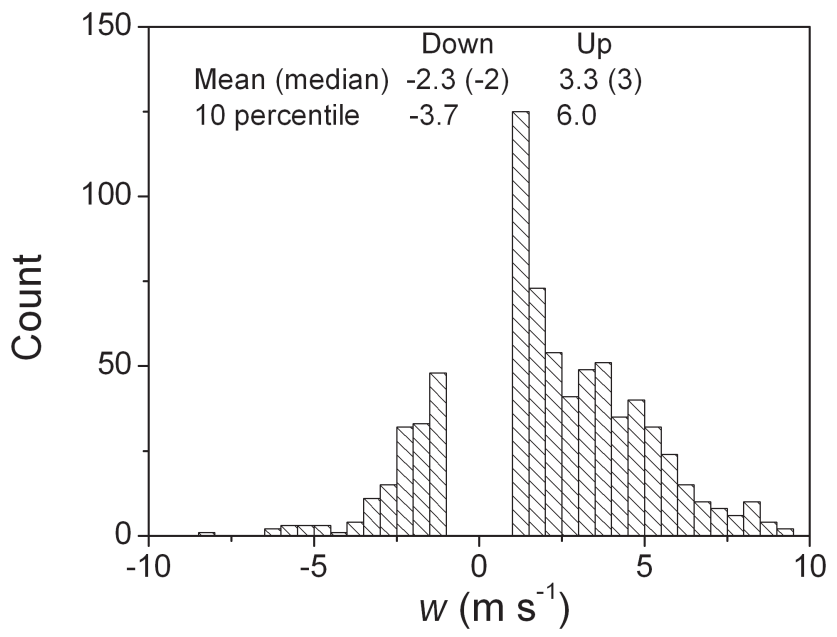

Fig. 3. Distribution of $w$ in draft cores in the tropopause region $(16-20 \mathrm{~km})$. The mean, median and strongest 10 percentile values of the population are also depicted on figure.

\subsection{Quantification of mass flux in cores}

It is interesting to note downdraft cores adjacent to and, sometimes, above updraft cores, in the vicinity of the tropopause. The downdraft cores are generally observed in the lower troposphere as a result of raindrop drag and evaporative subsidence. Sometimes, downdraft cores can be deep, which are generally seen in the transition phase of mesoscale convective systems (MCS) (May and Rajopadhyaya, 1999; Uma and Rao, 2009). The cores in the vicinity of the tropopause are a result of dynamical response of updrafts (Yuter and Houze, 1995) or high frequency gravity wave motions (Alexander et al., 1995). Although the processes responsible for downdrafts are known, the magnitude of vertical wind in cores, particularly in the tropopause region, is not known precisely. Figure 3 shows the distribution of $w$ in upand down-draft cores in the tropopause region (above $16 \mathrm{~km}$ ). It is evident from Fig. 3 that the downdrafts are present for considerable percentage of time with large magnitude. However, updrafts seem to be preponderant near the tropopause region. The updrafts are intense as well. Distribution for upand down-drafts shows large \% occurrence (estimated from counts) at weak drafts, but decays drastically with the increase in intensity of drafts. The distribution resembles with that of observed by air-crafts and profiler measurements elsewhere (Lemone and Zipser, 1980; Lucas et al., 1994; May and Rajopadhyaya, 1999). The mean, median and strongest 10 percentile population (given in Fig. 3) also shows the predominance of updrafts. The strongest 10 percentile drafts in the tropopause region are, in fact, nearly equal to that of in the lower and middle tropospheric observed/simulated draft cores (Xu and Randal, 2001, and references therein).

It is clearly apparent from Figs. 1 and 2 that the cores are penetrating the tropopause $(\sim 16 \mathrm{~km}$, as evidenced from rela-

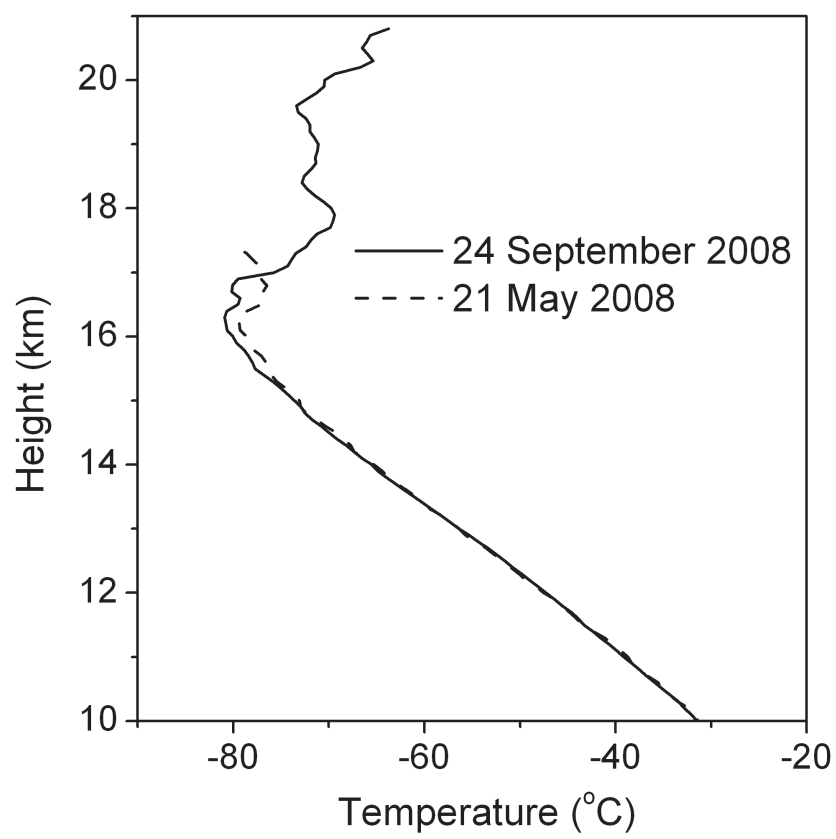

Fig. 4. Vertical profiles of temperature obtained from radiosondes, launched from Gadanki (at 15:00 LT on 21 May 2008 and at 17:00 LT on 24 September 2008). The cold point tropopause can be seen around $16.3 \mathrm{~km}$.

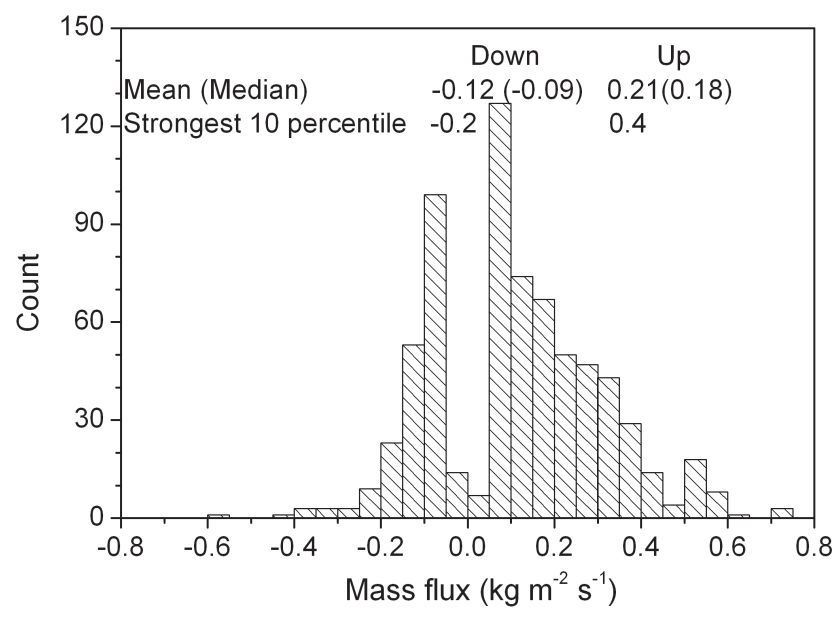

Fig. 5. The distribution for mass flux per unit volume across the tropopause.

tively large SNR and can also be obtained directly from temperature profiles (Fig. 4)) indicating that significant amount of mass exchange could have occurred during this period. The mass flux per unit volume is estimated from $w$ and $\rho$ values in the height region of $16-20 \mathrm{~km}$ from all case studies. The distribution for mass flux during overshooting convection (both up- and down-draft) is shown in Fig. 5. The distribution is wide varying from $-0.6 \mathrm{~kg} \mathrm{~m}^{-2} \mathrm{~s}^{-1}$ (downward flux) to $0.8 \mathrm{~kg} \mathrm{~m}^{-2} \mathrm{~s}^{-1}$ (upward flux), nevertheless such 


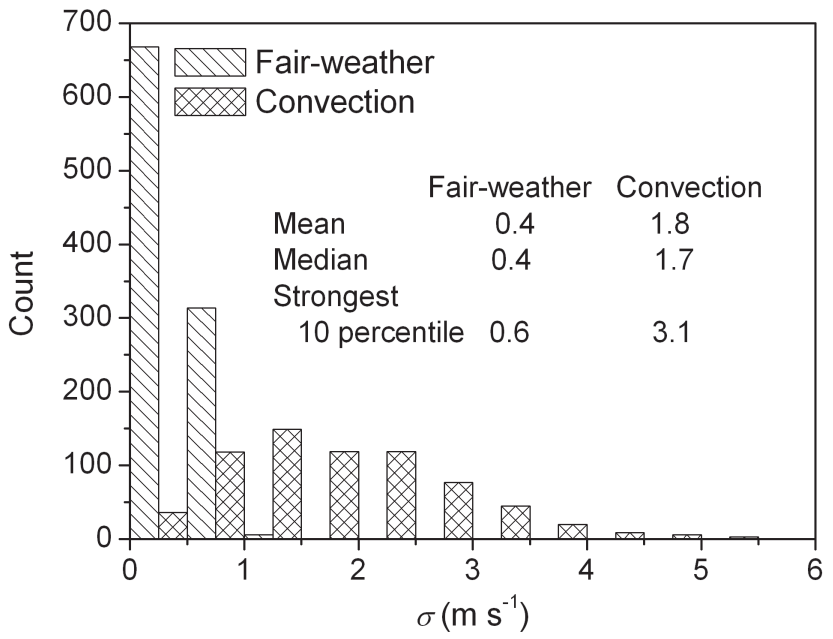

Fig. 6. Distribution for spectral width in fair-weather and convective cores in the tropopause region $(16-20 \mathrm{~km})$.

intense mass flux events are not common. Therefore, the mean mass flux with large standard deviation (due to the variation in fluxes within the storm and also from storm to storm) indicates that these estimates are of first order. The distribution clearly shows two peaks (one for upward and the other for downward fluxes) at $0.075 \mathrm{~kg} \mathrm{~m}^{-2} \mathrm{~s}^{-1}$. Although downward fluxes with large magnitude are present for considerable period, the net flux, residual of troposphere to stratosphere (upward) and stratosphere to troposphere (downward) flux, is upward. For instance, the mean upward mass flux is $0.177 \pm 0.13 \mathrm{~kg} \mathrm{~m}^{-2} \mathrm{~s}^{-1}$, while the downward flux is $0.092 \pm 0.04 \mathrm{~kg} \mathrm{~m}^{-2} \mathrm{~s}^{-1}$. The skewed distribution towards upward flux and the presence of large upward fluxes corroborate the general perception that the net STE in tropics due to convection is from the troposphere to stratosphere.

\subsection{Quantification of turbulence in draft cores}

In addition to the direct transport of constituents and mass into the stratosphere through overshooting convection, the exchange also occurs through turbulence diffusion processes. The turbulence mixing across cloud boundaries is one of the effective mechanisms by which the irreversible transfer of STE occurs (Sherwood and Dessler, 2000). The $\sigma$ measurements made with IMSTR during fair-weather and in convective cores are employed to quantify the turbulence. The distribution for $\sigma$ (a measure of turbulence) in draft cores near the vicinity of the tropopause $(16-20 \mathrm{~km})$ is shown in Fig. 6 . Also included in the figure is the distribution for $\sigma$ in fairweather conditions observed within 10 days from the convection day. Although the distributions for $\sigma$ in fair-weather and convection have a small overlap, but the mean (median) values differ by a large magnitude. For instance, the mean $\sigma$ for fair-weather $\left(0.4 \pm 0.14 \mathrm{~m} \mathrm{~s}^{-1}\right)$ is nearly 4.5 times smaller than that for draft cores $\left(1.8 \pm 0.96 \mathrm{~m} \mathrm{~s}^{-1}\right)$. The difference in

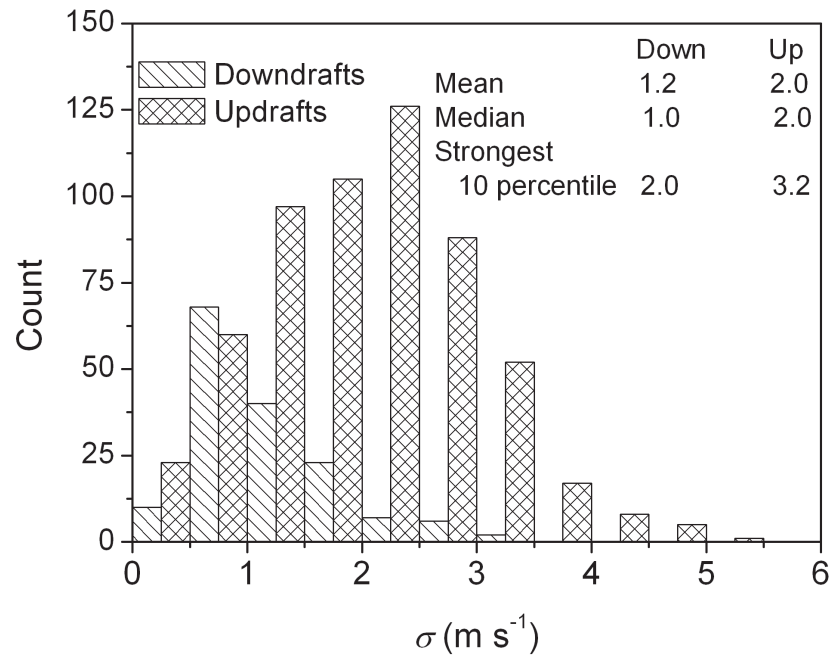

Fig. 7. Distribution of spectral width in up- and down-draft cores in the tropopause region $(16-20 \mathrm{~km})$.

mean $\sigma$ between fair-weather and convection is statistically significant. Further, the distribution for $\sigma$ in convection is much wider compared to that in fair-weather, indicating the large variability present in convection. Large spectral widths $\left(>4 \mathrm{~m} \mathrm{~s}^{-1}\right)$ are also observed in convection, but such large spectral widths existed for only $1 \%$ of total observations. Such large $\sigma$ values are, in fact, observed in the lower troposphere during convection (Rao et al., 1999). By knowing the water vapor (and its gradients), it is possible to estimate the water vapor fluxes across the cloud boundaries due to turbulence.

The spectral broadening in fair-weather (in the vicinity of the tropopause) is smaller at Gadanki than the values obtained at mid-latitude stations, for ex., Shigaraki, Japan $\left(0.6 \pm 0.2 \mathrm{~m} \mathrm{~s}^{-1}\right.$ (Alexander and Tsuda, 2007)), nevertheless, is comparable to that observed near the equatorial tropopause $\left(0.46 \pm 0.2 \mathrm{~m} \mathrm{~s}^{-1}\right.$, Fujiwara et al., 2003). On the other hand, earlier studies have shown that the turbulence strength increases when a propagating wave breaks near the tropopause and this enhanced turbulence is important for STE. Fujiwara et al. (2003) have shown Kelvin wave breaking and associated increase in turbulence strength using Equatorial Atmospheric Radar (EAR) measurements. They observed that the turbulent kinetic energy increases by a factor of 5 during wave break period compared to that of in quiet period. Whiteway et al. (2003) observed gravity wave breaking near the tropopause over Aberystwyth and subsequent intensifying of turbulence activity. The turbulence strength in such wave breaking events (maximum values in the range of 0.7 $1.2 \mathrm{~m} \mathrm{~s}^{-1}$ (Fujiwara et al., 2003; Whiteway et al., 2003)) is, indeed, large compared to that of in quite periods, but much smaller compared to that of in draft cores over Gadanki.

The turbulence strength is not same in up- and down-draft cores (Fig. 7). The $\sigma$ distribution for updraft cores is wide 

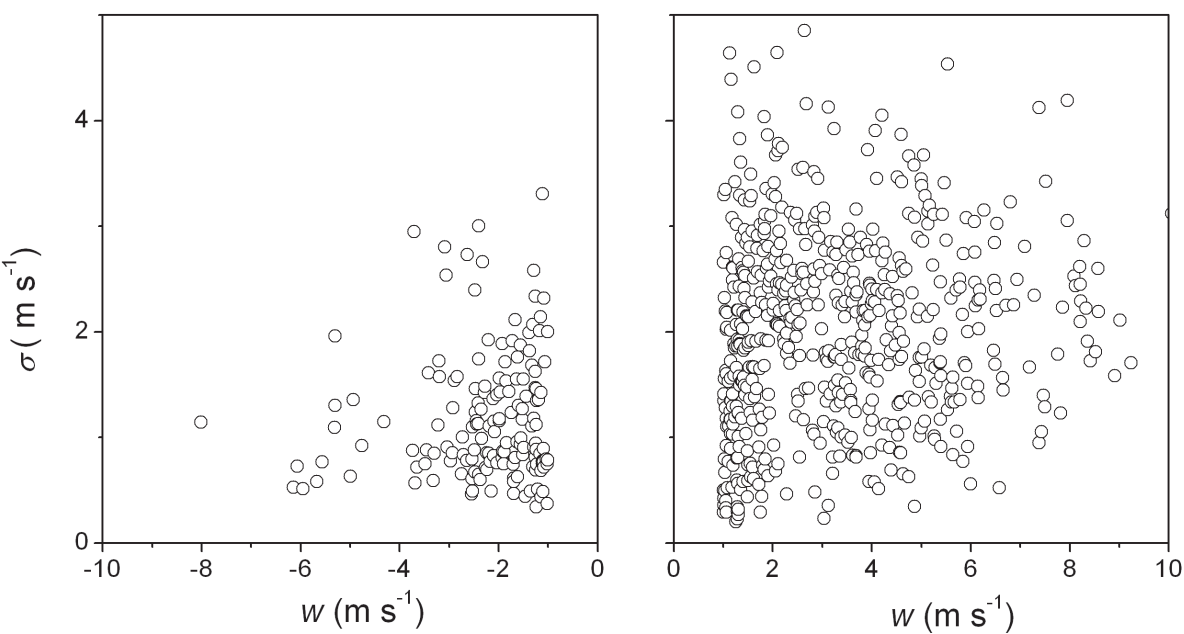

Fig. 8. Variation of spectral width as a function of $w$ in up- and down-draft cores.

and contains large values $\left(>2 \mathrm{~m} \mathrm{~s}^{-1}\right)$ of $\sigma$. On the other hand, the $\sigma$ distribution for downdraft cores is relatively narrow with most of the population $<2 \mathrm{~m} \mathrm{~s}^{-1}$. The mean, median and strongest 10 percentile values of $\sigma$ population for updraft cores are considerably larger than that for downdraft cores. Though the mean $\sigma$ is smaller for downdraft cores than for updraft cores, but is larger than that for fair-weather $\left(0.4 \mathrm{~m} \mathrm{~s}^{-1}\right)$.

To see whether the turbulence depends on the intensity of convection (gauged by vertical air motion), the $\sigma$ is plotted as a function of $w$ in up- and down-draft cores (Fig. 8). No clear discernable feature (in other words, do not follow any functional form), is observed from Fig. 8. For any particular vertical air motion, $\sigma$ has several values (wide distribution) in both up- and down-draft cores. However, the $\sigma$ distribution at any particular $w$ is wider for updraft cores than for downdraft cores.

\subsection{Uncertainty in the quantification of turbulence in draft cores}

Note that, the measured $\sigma$ by VHF radars contains nonturbulent contributions, due to finite beam width (beam broadening), vertical shear of horizontal wind (shear broadening) and transience (Hocking, 1985; Fukao et al., 1994; Nastrom et al., 1997; Rao et al., 2001; Wilson, 2004). The shear broadening can be neglected for vertical beams (Fukao et al., 1994). The beam broadening increases with beam width and wind speed. The reliability of wind profiler horizontal winds during convection is less (Hooper et al., 2005), because of implicit assumptions (homogeneity of wind with space - within the volume between probing beams and time - required to probe in at least 3 non-coplanar directions) involved in Doppler Beam Swinging (DBS) method, which are not true during convection. Therefore, the spectral width measurements are not corrected for beam broadening effects.
However, an estimate of beam broadening correction is made using the wind speed at the tropopause altitude prior to and after the convection overpass $\left(20-40 \mathrm{~m} \mathrm{~s}^{-1}\right)$. The correction due to finite beam for a given velocity range of $20-40 \mathrm{~m} \mathrm{~s}^{-1}$ is in the range of $0.38-0.76 \mathrm{~m} \mathrm{~s}^{-1}$.

In addition, the transience effect also needs to be considered here. In fair weather, the transience broadening is negligible; when the beam probing period and gradient in vertical wind within the radar pulse height are small, such as in the present study (16s and $300 \mathrm{~m}$, respectively). However, in convection, the vertical velocities change rapidly with time and therefore contribute to the spectral broadening even in such short beam probing periods. Similarly large vertical gradients in $w$ in $300 \mathrm{~m}$ also contribute to spectral broadening. To obtain the first order estimate of transience broadening, the difference in $w$ from successive $w$ wind profiles (44-s resolution) (within the cores near the tropopause) is estimated. Figure 9a shows the histogram of $w$-difference in $44 \mathrm{~s}$. It is apparent from the figure that $60 \%$ of $w$-difference population lies within $\pm 1 \mathrm{~m} \mathrm{~s}^{-1}$. The mean and median values of $w$-difference population (considering only magnitude) are also $\leq 1 \mathrm{~m} \mathrm{~s}^{-1}$. In other words, the $w$ changes by not more than $1 \mathrm{~m} \mathrm{~s}^{-1}$ in $44 \mathrm{~s}$ in majority of cases. Then the variance in $w$ in $16 \mathrm{~s}$ (beam probing time) is estimated from $1 \mathrm{~s}$ interpolated $w$-difference values. Similarly, the variance in $300 \mathrm{~m}$ is also estimated by identifying the limits in which most of the $w$-gradient population lies $\left( \pm 1 \mathrm{~m} \mathrm{~s}^{-1}\right.$ in this case) (Fig. 9b). The variance (estimated using the procedure outlined above) in $w$ in $16 \mathrm{~s}$ and in $300 \mathrm{~m}$ are $0.013 \pm 0.01$ and $0.08 \pm 0.07 \mathrm{~m}^{2} \mathrm{~s}^{-2}$, respectively. Even if we consider the velocity difference between successive scan cycles (height ranges) is $2.5 \mathrm{~m} \mathrm{~s}^{-1}$ in $44 \mathrm{~s}$ (in $\left.300 \mathrm{~m}\right)(90 \%$ of $w$ differences are within this limit), the variance in $16 \mathrm{~s}$ (in $300 \mathrm{~m}$ height) is not more than $0.08\left(0.52 \mathrm{~m}^{2} \mathrm{~s}^{-2}\right)$. 

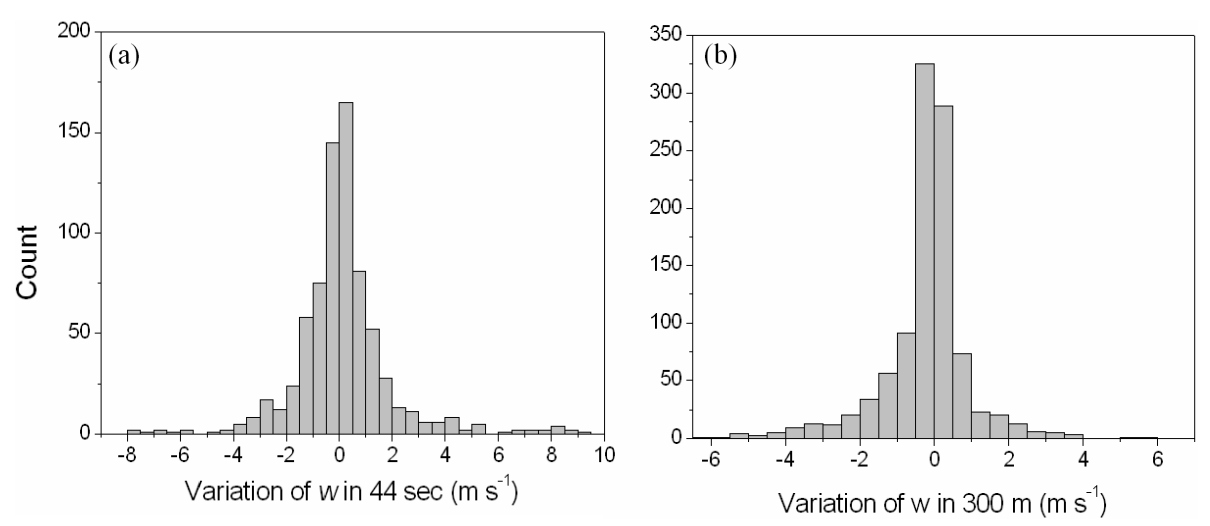

Fig. 9. Distributions for the variation of $w$ (a) in $44 \mathrm{~s}$ and (b) in $300 \mathrm{~m}$, respectively.

Removing the above uncertainities/non-turbulent contributions from the observed spectral broadening, the mean $\sigma^{2}$ due to turbulence alone is found to be $>2 \mathrm{~m}^{2} \mathrm{~s}^{-2}$. For a typical tropopause brunt-vaisala frequency $(N)$ of $0.02 \mathrm{~s}^{-1}$, the estimated vertical eddy diffusivity $(K)$ will be of the order of $10 \mathrm{~m}^{2} \mathrm{~s}^{-1}$ (see Fukao et al., 1994; Rao et al., 2001, for formulation of $K$ ). The estimated $K$ is larger than those reported elsewhere using air-craft (except in extremely turbulent patches), radar and lidar measurements (see Table 1 of Wilson, 2004). The early estimations of $K$ by Kennedy and Shapiro (1980) in extremely turbulent patches are of the order of $2-111 \mathrm{~m}^{2} \mathrm{~s}^{-1}$. In fact, $K$ estimated from strongest 10 percentile values of $\sigma$ (Fig. 6) is found to be of the same order.

\section{Summary and future perspectives}

Coordinated measurements with IMSTR and radiosonde during the passage of convection are used to quantify mass flux and turbulent flux across the tropopause in draft cores. The important conclusions obtained from the present study are listed below.

1. It is widely accepted that the exchange between the troposphere and stratosphere in tropics occurs primarily through two mechanisms; a fast transport by convection and a slow transport by stratospheric diabatic circulation. Earlier studies have shown that the mass flux due to diabatic circulation is from the troposphere to stratosphere in tropics (Rosenlof, 1995; Holton et al., 1995; Sherwood, 2000). The present study shows that the transport due to convection can be in both ways, as evidenced by the wide distribution of up- and downward fluxes. Nevertheless, the population and also the mean value of mass flux are larger in updraft cores, and suggest that the net flux due to convection is also from the troposphere to stratosphere in these cases. The large variation in the flux values (and large standard deviation) indicates that the mean value obtained here is of first order and the mass flux can vary significantly from one event to the other.

The present analysis clearly shows that mass flux across the tropopause in penetrative convection, both by direct intrusions and turbulence, is significant. Nevertheless, the frequency occurrence of such penetrative cumulus convection is not known from the present analysis. Further, such convective exchange could exhibit large spatial and temporal variabilities. Considerable observational support can be found for the existence of some amount of overshooting past the tropical tropopause. Frequent overshooting has been inferred from satellite data by Schmetz et al. (1997). Gettleman (2002) also used satellite data to map the geographical variability and frequency of occurrence of convection. Recently, using Tropical Rainfall Measuring Mission (TRMM) precipitation radar measurements, Liu and Zipser (2005) have shown that $0.1 \%$ of convection penetrated the $380 \mathrm{~K}$ potential temperature level. The above studies have shown that overshooting convection is more frequent over land than over water, especially over central Africa, Indonesia and South America. Combining such statistics on the occurrence of convection (both in space and frequency) with the present study (dealing with the direct measurement of mass flux and turbulence flux) will advance our understanding of convective transport of mass and constituents across the tropopause. To obtain such an estimate, it is planned to take concurrent measurements of $w$ and $\sigma$ with IMSTR and vertical sounding of meteorological variables with radiosonde during the passage of several draft cores over the observational site (as part of SAFAR campaign).

2. A clear enhancement in turbulence activity is observed in draft cores. The magnitude of turbulence strength is nearly 4.5 times larger in convective cores than in fair weather. The strength of turbulence in convection is higher than that of due to wave breaking near the 
tropopause reported elsewhere (Kelvin waves by Fujiwara et al., 2003; and gravity waves by Whiteway et al., 2003). The turbulence strength is higher in updraft cores than in downdraft cores. Further, the turbulence strength does not show any systematic variation with the intensity of convection, gauged by the magnitude of $w$, in up- and down-draft cores.

The present study clearly shows the enhancement in turbulence during convection. Recent studies have reported moderate-marginally severe turbulence not only in active convection regions but also far away from active convection (Trier and Sharman, 2009 and references therein). Several mechanisms are proposed for the initiation of convection induced turbulence, starting from high-frequency gravity wave breaking (Lane and Sharman 2008) to localized reductions of Richardson number resulting from circulations generated by convection and to dynamic instability by vertical shear of horizontal wind beneath the outflow (Trier and Sharman, 2009). By combining scanning radar and IMSTR measurements, it is possible to infer such information in future.

Acknowledgements. Topical Editor F. D'Andrea thanks two anonymous referees for their help in evaluating this paper.

\section{References}

Alexander, S. P. and Tsuda, T.: Measurements of vertical eddy diffusivity across the tropopause using radio acoustic sounding system (RASS), Geophys. Res. Lett., 34, L06803, doi:10.1029/2006GL028753, 2007.

Alexander, M. J., Holton, J. R., and Durran, D. R.: The gravity wave response above deep convection in a squall line simulation, J. Atmos. Sci., 52, 2212-2232, 1995.

Cifelli, R., Peterson, W. A., Carry, L. D., and Rutledge, S. A.: Radar observations of the kinematic, microphysical and precipitation characteristics of two MCS's in TRMMLBA, J. Geophys. Res., 107, 8077, doi:10.1029/2000JD000264, 2002.

Corti, T., Luo, B. P., de Reus, M., Brunner, D., Cairo, F., et al.: Unprecedented evidence for deep convection hydrating the tropical stratosphere, Geophys. Res. Lett., 35, L10810, doi:10.1029/2008GL033641, 2008.

Danielsen, E. F.: In situ evidence of rapid, vertical, irreversible transport of lower tropospheric air into the lower tropical stratosphere by convective cloud turrets and by larger-scale upwelling in tropical cyclones, J. Geophys. Res., 98(D5), 8665-8681, 1993.

Dhaka, S. K., Choudary, S. M., Shibagaki, Y. S., Yamanaka, M. D., and Fukao, S.: Observable signatures of a convectively generated wave field over the tropics using Indian MST radar at Gadanki (13.5 N, 79.2 E), Geophys. Res. Lett., 29, 1872-1875, 2002.

Fujiwara, M., Yamamoto, M. K., Hashiguchi, H., Horinouchi, T., and Fukao, S.: Turbulence at the tropopause due to breaking Kelvin waves observed by the Equatorial Atmospheric Radar, Geophys. Res. Lett., 30, 1171, doi:10.1029/2002GL016278, 2003.
Fukao, S., Yamanaka, M., Ao, N., Hocking, W. K., Sato, T., Yamamoto, M., Nakamura, T., Tsuda, T., and Kato, S.: Seasonal variability of vertical eddy diffusivity in the middle atmosphere: 1. Three-year observations by the middle and upper atmosphere radar, J. Geophys. Res., 99, 18973-18987, 1994.

Gettelman, A., Salby, M. L., and Sassi, F.: Distribution and influence of convection in the tropical tropopause region, J. Geophys. Res., 107(D10), 4080, doi:10.1029/2001JD001048, 2002.

Hocking, W. K.: Measurement of turbulent energy dissipation rates in the middle atmosphere by radar techniques: A review, Radio Sci., 20, 1403-1422, 1985.

Holton, J. R., Haynes, P. H., McIntyre, M. E., Douglass, A. R., Rood, R. B., and Pfister, L.: Stratosphere-troposphere exchange, Rev. Geophys., 33, 403-439, 1995.

Hooper, D. A., McDonald, A. J., Pavelin, E., Carey-Smith, T. K., and Pascoe, C. L.: The signature of mid-latitude convection observed by VHF wind-profiling radar, Geophys. Res. Lett., 32, L04808, doi:10.1029/2004GL020401, 2005.

Jain, A. R., Rao, Y. J., Patra, A. K., Rao, P. B., Viswanathan, G., and Subramanian, K.: Observations of tropical convection events using Indian MST radar: First results, Q. J. Roy. Meteorol. Soc., 126, 3097-3115, 2000.

Kennedy, P. J. and Shapiro, M. A.: Further encounters with clear air turbulence in research aircraft, J. Atmos. Sci., 37, 986-993, 1980.

Kumar, K. K.: VHF radar observations of convectively generated gravity waves: Some new insights,Geophys. Res. Lett., 33, L01815, doi:10.1029/2005GL024109, 2006.

Lane, T. P. and Sharman, R. D.: Some influences of background flow conditions on the generation of turbulence due to gravitywave breaking above deep convection, J. Appl. Meteor. Climatol., 47, 2777-2796, 2008.

LeMone, M. A. and Zipser, E. J.: Cumulonimbus vertical velocity events in GATE. Part I: Diameter, intensity and mass flux, J. Atmos. Sci., 37, 2444-2457, 1980.

Liu, C. and Zipser, E. J.: Global distribution of convection penetrating the tropical tropopause, J. Geophys. Res., 110, D23104, doi:10.1029/2005JD006063, 2005.

Lucas, C., Zipser, E. J., and LeMone, M. A.: Vertical velocity off tropical Australia, J. Atmos. Sci., 51, 3183-3193, 1994.

May, P. T. and Rajopadhyaya, D. K.: Vertical velocity characteristics of deep convection over Darwin, Australia, Mon. Weather Rev., 127, 1056-1071, 1999.

Nastrom, G. D. and Eaton, F. D.: A brief climatology of eddy diffusivities over White Sands missile range, New Mexico, J. Geophys. Res., 102, 29819-29826, 1997.

Nastrom G. D. and Eaton, F. D.: Seasonal variability of turbulence parameters at 2 to $21 \mathrm{~km}$ from MST radar measurements at Vandenberg Air Force Base, California, J. Geophys. Res., 110, D19110, doi:10.1029/2005JD005782, 2005.

Rajeevan, M., Kesarkar, A., Thampi, S. B., T. N. Rao, B. Radhakrishna, and M. Rajasekhar: Sensitivity of cloud resolving simulations of a severe thunderstorm to cloud microphysics, Ann. Geophys., in review, 2010.

Rao, D. N., Rao, T. N., Ratnam, M. V., Thulasiraman, S., Rao, S. V. B., Srinivasulu, P., and Rao, P. B.: Diurnal and seasonal variability of turbulence parameters observed with Indian MesosphereStratosphere-Troposphere radar, Radio Sci., 36, 1439-1457, 2001. 
Rao, P. B., Jain, A. R., Kishore, P., Balamuralidhar, P., Damle, S. H., and Viswanathan, G.: Indian MST radar, 1. System description and sample vector wind measurements in ST mode, Radio Sci., 30, 1125-1138, 1995.

Rao, T. N., Rao, D. N., and Raghavan, S.: Tropical precipitating systems observed with Indian MST radar, Radio Sci., 5, 11251139, 1999.

Rosenlof, K. H.: The seasonal cycle of the residual mean meridional circulation in the stratosphere, J. Geophys. Res., 100, 51735191, 1995.

Schmetz, J., Tjemkes, S. A., Gube, M., and van de Berg, L.: Monitoring deep convection and convective overshooting with METEOSAT, Adv. Space Res., 19, 433-441, 1997.

Sherwood, S. C.: A stratospheric "drain" over the maritime continent, Geophys. Res. Lett., 27, 677-680, 2000.

Sherwood, S. C. and Dessler, A. E.: On the control of stratospheric humidity, Geophys. Res. Lett., 27, 2513-2516, 2000.

Sherwood, S. C. and Dessler, A. E.: A model for transport across the tropical tropopause, J. Atmos. Sci., 58, 765-779, 2001.
Trier, S. B. and Sharman, R. D.: Convection-permitting simulations of the environment supporting widespread turbulence within the upper-level outflow of a mesoscale convective system, Mon. Weather Rev., 137, 1972-1990, 2009.

Uma, K. N. and Rao, T. N.: Characteristics of vertical velocity cores in different convective systems observed over Gadanki, India, Mon. Weather Rev., 137, 953-977, 2009.

Whiteway, J. A., Pavelin, E. G., Busen, R., Hacker, J., and Vosper, S.: Airborne measurements of gravity wave breaking at the tropopause, Geophys. Res. Lett., 30, 2070, doi:10.1029/2003GL018207, 2003.

Wilson, R.: Turbulent diffusivity in the free atmosphere inferred from MST radar measurements: a review, Ann. Geophys., 22, 3869-3887, 2004, http://www.ann-geophys.net/22/3869/2004/.

$\mathrm{Xu}$, K.-M. and Randall, D. A.: Updraft and downdraft statistics of simulated tropical and midllatitude cumulus convection, J. Atmos. Sci., 58, 1630-1649, 2001.

Yuter, S. E. and Houze Jr., R. A.: Three-dimensional kinematic and microphysical evaluation of Florida cumulonimbus, Part II: Frequency distributions of vertical velocity, reflectivity, and differential reflectivity, Mon. Weather Rev., 123, 1941-1963, 1995. 